九州大学学術情報リポジトリ

Kyushu University Institutional Repository

\title{
Specific Difference in Photorespiration Activity in C4 Subtype Plants and Its Relationship with Drought Tolerance of Leaf Photosynthesis
}

\section{Sato, Azusa}

Laboratory of Plant Production Physiology, Division of Soil Science and Plant

Production, Graduate School of Bioresouce and Bioenvironmental Sciences, Kyushu University

Kubota, Fumitake

Laboratory of Plant Production Physiology, Division of Soil Science adn Plant

Production, Department of Plant Resoruces, Faculty of Agriculture, Kyushu University

https://doi.org/10.5109/4561

出版情報: 九州大学大学院農学研究院紀要. 49 (1)，pp.25-32，2004-02-01. Faculty of Agriculture， Kyushu University

バージョン :

権利関係 : 


\title{
Specific Difference in Photorespiration Activity in C4 Subtype Plants and Its Relationship with Drought Tolerance of Leaf Photosynthesis
}

\author{
Azusa SATO ${ }^{1 *}$ and Fumitake KUBOTA \\ Laboratory of Plant Production Physiology, Division of Soil Science and Plant Production, \\ Department of Plant Resources, Faculty of Agriculture, \\ Kyushu University, Fukuoka 812-8581, Japan \\ (Received October 27, 2003 and accepted November 14, 2003)
}

\begin{abstract}
Carbon dioxide gas exchange rate (CER), stomatal conductance (Gs), and photosystem II quantum yield $(\Phi \mathrm{e})$ were measured with three $\mathrm{C} 4$ subtype plants, corn (Zea mays L., NADP-ME type), common millet (Panicum miliaceum L., NAD-ME type), guineagrass (Panicum maximum Jacq., PEP-CK type) and a C3 type plant, mung bean (Vigna radiata L.) grown in droughts. The specific difference in drought tolerance in photosynthesis was discussed in relation to their photorespiratory activity. The $\mathrm{C} 4$ plants were superior to mung bean in both photosynthetic sustainability in droughts and photosynthetic recovery under re-watering after droughts. CER and $\Phi$ e of corn showed a large reduction with a lenient decrease in leaf water potential $\left(\Psi_{\mathrm{L}}\right)$ compared to those of the other two subtypes. In both guineagrass and common millet $\Phi$ e was sustained at a relatively higher level when their CER was decreased in droughts. A similar specific feature to this was found in leaves measured in the air with low $\mathrm{CO}_{2}$. concentrations. This may suggest that there is an inter-subtype difference in photorespiration activity. Having a higher photorespiration activity is regarded as a cause for guineagrass and common millet to have superiority in drought tolerance. The inter-subtype difference in photorespiration activity was also able to be estimated from $\Phi$ e of film-sealed leaves.
\end{abstract}

\section{INTRODUCTION}

Today the global warming and its resultant climatic fluctuations are widely predicted. Water is one of the important climatic factors regulating the photosynthesis and production of crops, and the yield reductions of crops due to drought stresses have been frequently reported recently. As a counter measure against this, it is required to release cultivars having a high tolerance under drought stresses and also establish feasible water saving agricultural systems.

Crops included in the $\mathrm{C} 4$ type are known to have a high tolerance against drought conditions. The C4 type plants are divided into three sub-types such as NADP-ME, NAD-ME and PEP-CK based on the kind of decarboxylation enzymes and the morphological feature in vascular bundle sheath cells. To compare the specific difference in drought-tolerance among C4 subtypes is interesting in understanding the relationship between photosynthetic metabolism and drought tolerance. Though the difference in photosynthetic activity has not always been significantly determined among the

\footnotetext{
1 Laboratory of Plant Production Physiology, Division of Soil Science and Plant Production, Graduate School of Bioresource and Bioenvironmental Sciences, Kyushu University

* Corresponding author (E-mail: unos@agr.kyushu-u.ac.jp)
} 
sub-types, there are some reports describing that the inter-subtype difference was found in the photosynthetic response in plants grown under drought conditions (Xu et al., 1996; Nagasuga et al., 2002).

It may be predicted that a more distinctive feature is shown in photosynthetic parameters in each C4 subtype plant, if they are exposed to drought conditions. With this prediction our experiment was designed and carried out using four materials such as corn (Zea mays L., NADP-ME type), common millet (Panicum miliaceum L., NAD-ME subtype), guineagrass (Panicum maximum Jacq., PEP-CK subtype) and mung bean (Vigna radiata L., C3 type). We tried here to clarify the specific and inter-subtype features in photosynthetic and photorespiratory responses on the basis of gas exchange rate and chlorophyll fluorescence intensity measured in drought-stressed plants, and discussed the relationship between photorespiratory activity and drought-tolerance in $\mathrm{C} 4$ subtypes. Furthermore, as an easy method to find the potential activity of photorespiration in C4 plants we employed the leaf-sealing method (Haimeirong et al., 2002) and discussed its usefulness for checking the drought tolerance of $\mathrm{C} 4$ subtypes.

\section{MATERIALS AND METHODS}

\section{Experimental materials and growth conditions}

As experimental materials used are four species: three C4 subtype plants such as corn (Zea mays L., NADP-ME type), common millet (Panicum miliaceum L., NAD-ME type) and guineagrass (Panicum maximum Jacq., PEP-CK type), and a C3 type plant, mung bean (Vigna radiata L.). The plants were grown in $8 \mathrm{~L}$ pots containing sandy soil in the experimental farm of Kyushu University ( $33^{\circ} 35^{\prime} \mathrm{N}, 130^{\circ} 23^{\prime} \mathrm{E}$ ) during June to August in 2002. As the basal fertilization, a chemical compound fertilizer $\left(\mathrm{N}_{2}: \mathrm{P}_{2} \mathrm{O}_{5}: \mathrm{K}_{2} \mathrm{O}=\right.$ 16:16:16 in weight percentage) was used $5 g$ per pot.

\section{Treatments}

Plants were grown for 40 days under adequately watered soil conditions, before a drought stress was imposed to plants by cutting water supply for two days, and photosynthetic responses to the treatment were measured. Directly after the drought treatment, the plants were re-watered, and their recovery responses were observed 24 hours later. The measurement parameters were described below.

\section{Measurements of leaf water potential $\left(\Psi_{L}\right)$ and soil water potential ( $\Psi_{S}$ )}

Leaf discs of $6 \mathrm{~mm}$-diameter were cut off from an adjacent area of the leaf part used for $\mathrm{CO}_{2}$ exchange rate (CER) measurement by an assimilation chamber. Directly after this; each of the leaf discs was placed in the chamber of a psychrometer (C-52, Wescor, USA) and $\Psi_{\mathrm{L}}$ was measured 3 hours later. At the same time, soil was sampled from three parts in a pot by using a sampling cylinder of $17 \mathrm{~mm}$ in diameter, and $\Psi_{\mathrm{S}}$ was measured with a psychrometer (WP4, Decagon; USA).

\section{Measurements of CER and chlorophyll fluorescence (CF)}

Fully expanded active leaves were used for measurements. CER and CF were simultaneously measured with a sandwich-type assimilation chamber and a fluorescence meter 
(PAM2000, Walz, Germany), respectively.

The measured leaf area inside the assimilation chamber was $5.5 \mathrm{~cm}^{2}$. A metal-haloid lamp (LS-M180, Sumita-Glass, Japan) was used as a light source and the light intensity supplied to leaf surface was fixed at $504 \mu \mathrm{mol} \mathrm{m}^{-2} \mathrm{~s}^{-1}$. Light intensity was measured with a light meter (LI-189, LI-COR, USA). The temperature of leaf was regulated at $30 \pm 1^{\circ} \mathrm{C}$.

Carbon dioxide concentrations and water vapor deficits in the air sampled at the inlet and outlet of the assimilation chamber were measured with an infra-red analyzer (LI-6262, LI-COR, USA). The relative humidity in the air pumped into the assimilation chamber was adjusted at 50\% using a dew point generator (LI-610, LI-COR, USA). The rate of air flown to the assimilation chamber was $1.00 \mathrm{~L} \mathrm{~min}^{-1}$.

The concentration ratio of $\mathrm{CO}_{2}, \mathrm{O}_{2}$ and $\mathrm{N}_{2}$ in the air was controlled with a gas mixture (GM-3A, KOFLOC, Japan). The concentration of $\mathrm{CO}_{2}$ was finely controlled in the range from 0 to $367 \mu \mathrm{LL}^{-1}$ by passing the air through a cylinder stuffed with soda lime as a $\mathrm{CO}_{2}$ absorbent. The concentration of $\mathrm{O}_{2}$ was measured with an oxygen meter (LC-750, TORAY, Japan).

During the measurement of CER, CF was periodically monitored by hitting a white light pulse $(0.8 \mathrm{sec})$ of $8000 \mu \mathrm{mol} \mathrm{m} \mathrm{m}^{-2} \mathrm{~s}^{-1}$ to a leaf placed in the assimilation chamber. Photosystem II quantum yield ( $\Phi_{\mathrm{e}}$ ) was calculated by the equation (1) according to the method described by Genty et al. (1989) and Bilger et al. (1990).

$$
\Phi \mathrm{e}=\left(\mathrm{Fm} \mathrm{m}^{\prime} \mathrm{Fs}\right) / \mathrm{Fm}
$$

Where Fs is a CF determined at the light intensity of $504 \mu \mathrm{mol} \mathrm{m}^{-2} \mathrm{~s}^{-1}$ supplied for photosynthesis, and Fm' is a spike value of $\mathrm{CF}$ obtained when a light pulse of $8000 \mu \mathrm{mol}$ $\mathrm{m}^{-2} \mathrm{~s}^{-1}$ was supplied.

\section{Measurement of CF with a film-sealed leaf}

In advance of the measurement of a sealed leaf, CER and $\Phi$ e were determined using a leaf with full opened stomata under the atmospheric $\mathrm{CO}_{2}$ concentration, a light intensity of $504 \mu \mathrm{mol} \mathrm{m}^{-2} \mathrm{~s}^{-1}$ and a leaf temperature of $30 \pm 1{ }^{\circ} \mathrm{C}$. The light pulse for $\mathrm{CF}$ spike measurement was $0.8 \mathrm{sec}$ of $8000 \mu \mathrm{mol} \mathrm{m}^{-2} \mathrm{~s}^{-1}$. Then both surfaces of this leaf were sealed with transparent films to halt the gas exchange between leaf and the atmosphere, and a stable value of $\Phi$ e was determined 10 min after sealing.

\section{RESULTS AND DISCUSSION}

The parameter values of $\Psi_{\mathrm{L}}, \Psi_{\mathrm{S}}, \mathrm{CER}$, e and stomatal conductance (Gs) are compared among the four species, and the effect of drought treatment on these parameters are shown in Table1. In control pots without drought treatment, $\Psi$ s ranged from -0.43 to $-0.5 \mathrm{MPa}$, showing no or little difference in soil water condition where the four species had been grown. On the other hand, a significant difference was found between them under drought conditions: $\Psi_{S}$ in common millet and guinea grass had a relatively high value showing $-1.49 \mathrm{MPa}$ and $-1.51 \mathrm{MPa}$, respectively; while the values of corn and mung bean greatly decreased to $-2.87 \mathrm{MPa}$ and $-3.44 \mathrm{MPa}$, respectively.

$\Psi_{\mathrm{L}}$ in control plants of the four species was more than $-0.38 \mathrm{MPa}$. Under drought conditions the parameter values of corn and mung bean were, $-1.29 \mathrm{MPa}$ and $-1.50 \mathrm{MPa}$, 
respectively, relatively high values among the four species. On the other hand, those of common millet and guinea grass greatly reduced to $-2.10 \mathrm{MPa}$ and $-2.30 \mathrm{MPa}$, respectively. Of the three $\mathrm{C} 4$ subtypes, corn was characterized by having a lenient depression in $\Psi_{\mathrm{L}}$ under drought conditions.

A large reduction was found in CER of corn under drought condition; on the other hand, the drop of CER by the drought treatment was small in common millet and guineagrass. The ratio of CER in drought to the control value was in the order of common millet $(67.2 \%)$, guineagrass $(37.2 \%)$, corn (27.2\%) and mung bean (17.6\%). It is well known that a larger depression found in the ratio in C3 plants compared to C4 plants, and the former is inferior in drought tolerance to the latter. In our experimental results, we were interested in the fact that under drought conditions, corn had a less decrease in $\Psi_{\mathrm{L}}$ and had a large depression in CER compared to the other two C4 subtype species.

The response of Gs to droughts was almost similar in tendency to that of CER, which may suggest that CER was chiefly restricted by Gs, or stomatal aperture. A largest depression in $\Phi$ e was detected in corn among the three C4 subtypes. Though showing a large drop in CER as mentioned above, mung bean kept a higher $\Phi$ e under drought conditions. In C3 plants, Фe usually holds a high level even when CER has been considerably reduced because chemical energy from the photosystem has been consumed by photorespiratory metabolisms; therefore, a linear relationship is not well established between both parameters. On the other hand, C4 plants with no or little photorespiratory activity lead to have a linear relationship between $\Phi$ e and CER (Krall et al., 1992).

As shown in Table 1, the re-watering after the drought treatment gave different recovering effects on CER, Gs and $\Phi e$ among the four species. The recovery ratios in these parameters were lower in mung bean; for example, the ratio of CER was as low as

Table 1. Soil water potential, leaf water potential, $\mathrm{CO}_{2}$ exchange rate (CER), quantum yield ( $\Phi$ e) and stomatal conductance (Gs) in corn (NADP-ME type), common millet (NAD-ME), guineagrass (PEP-CK type) and mung bean (C3 plant) under well-watered, drought and re-watered conditions.

\begin{tabular}{|c|c|c|c|c|c|c|}
\hline & \multicolumn{3}{|c|}{ Corn (C4 plant, NADP-ME) } & \multicolumn{3}{|c|}{ Common millet (C4 plant, NAD-ME) } \\
\hline & well-watered & drought & re-watered & well-watered & drought & re-watered \\
\hline Soil water potential (MPa) & -0.48 & -3.44 & & -0.45 & -1.49 & \\
\hline Leaf water potential (MPa) & -0.35 & -1.29 & & -0.25 & -2.10 & \\
\hline $\mathrm{CER}\left(\mu \mathrm{mol} \mathrm{CO} \mathrm{m}^{-2} \mathrm{~s}^{-1}\right)$ & $19.4(100)$ & $1.4(27.2)$ & $16.7(86.1)$ & $19.5(100)$ & $13.1(67.2)$ & $18.8(96.4)$ \\
\hline$\Phi \mathrm{e}$ & 0.52 & 0.08 & 0.50 & 0.50 & 0.41 & 0.52 \\
\hline $\mathrm{Gs}\left(\mathrm{mol} \mathrm{H} \mathrm{H}_{2} \mathrm{O} \mathrm{m}^{-2} \mathrm{~s}^{-1}\right)$ & 0.21 & 0.01 & 0.15 & 0.16 & 0.08 & 0.21 \\
\hline
\end{tabular}

\begin{tabular}{lcccccc}
\hline & \multicolumn{2}{c}{ Guineagrass (C4 plant, PEP-CK) } & \multicolumn{3}{c}{ Mungbean (C3 plant) } \\
& well-watered & drought & re-watered & well-watered & drought & re-watered \\
\hline Soil water potential $(\mathrm{MPa})$ & -0.5 & -1.51 & & -0.43 & -2.87 & \\
Leaf water potential $(\mathrm{MPa})$ & -0.31 & -2.30 & & -0.38 & -1.50 & \\
$\mathrm{CER}\left(\mu \mathrm{mol} \mathrm{CO} \mathrm{m}^{-2} \mathrm{~s}^{-1}\right)$ & $21.5(100)$ & $8.0(37.2)$ & $19.5(90.6)$ & $16.9(100)$ & $2.9(17.6)$ & $8.1(47.9)$ \\
$\Phi \mathrm{e}$ & 0.55 & 0.29 & 0.52 & 0.56 & 0.35 & 0.47 \\
$\mathrm{Gs}\left(\mathrm{mol} \mathrm{H}_{2} \mathrm{O} \mathrm{m}^{-2} \mathrm{~s}^{-1}\right)$ & 0.19 & 0.10 & 0.19 & 0.35 & 0.03 & 0.23 \\
\hline
\end{tabular}


$47.9 \%$. In both common millet and guineagrass a considerable recovery was found in CER, and also Gs and $\Phi$ e retuned up to the pre-treatment levels, though the recovery ratio in these parameters was inferior in corn. When considering the less recovering ability together with the finding that a large drought-induced reduction in CER of this species, corn (NADP-ME) is presumed to be less tolerable to drought stresses compared to the other two C4 subtypes.

The drought tolerance in crops has been discussed from various physio-ecological and morphological view points related to cultivating managements. When the discussion is limited here to the photosynthesis of a leaf, it may be suggested that if there are some metabolisms consuming chemical energy when stomata are closed under drought condition, the photosynthetic system can be effectively protected against the photo-hazard caused by excessive energy accumulation in leaf. We placed a focus here on photorespiration as an energy consuming metabolism. The existence of photorespiration metabolism in C4 plants was biochemically and morphologically demonstrated by Ueno et al. (2001), and the inter-subtypical and inter-specific differences in photorespiration activity were described by $\mathrm{Ku}$ et al. (1974), Sato et al. (2001) and Yoshimura et al. (2003). According to these studies, the biochemical and morphological foundations for photorespiration is likely inferior in NADP-ME subtype plants to those of NAD-ME and PEP-CK subtype plants. Furthermore Yoshimura et al. (2003) predicted the specific difference in photorespiration activity in plants belonging to the same subtype. If photorespiratory activity is different among the C4 subtypes used here, it may be predicted that the amount of consumption in chemical energy is different among the subtypes and this results in affecting the relationship between CER and $\Phi$ e.

To verify this prediction, the CER- $\Phi$ e regression lines determined based on all the measurements obtained under control and treated plants are compared among the four species in Fig. 1. A linear relationship was found between these two parameters in all the four species. The $\mathrm{C} 3$ species showed a high $\Phi \mathrm{e}$, having a lenient slope in the regression line compared to the $\mathrm{C} 4$ species. This may be caused by the difference in photorespiratory activity between C3 and C4 plants as mentioned above. Among the three C4 subtypes, a specific difference was found in the inclination of regression lines between CER and $\Phi$ e. At high CER levels like about $20 \mu \mathrm{mol} \mathrm{m}^{-2} \mathrm{~s}^{-1}$, the inter-subtype difference was not found in $\Phi$ e among the subtypes, but as CER decreased the inter-subtype difference in $\Phi$ e increased. Particularly $\Phi$ e of corn was higher than those of common millet and guineagrass when they were compared at low CER levels. In the case CER decreased by stomatal closure under drought conditions, the inter-cellular $\mathrm{CO}_{2}$ concentration in leaf is depressed and this may cause the promotion of photorespiration. It may be predicted that the photorespiratory metabolism is more activated in common millet and guineagrass under drought conditions, by which their $\Phi$ e is allowed to hold a higher level. In other words, the photorespiration was hardly enhanced in corn leaf under drought conditions.

As the next step to get an additional verification of the prediction mentioned above, CER and $\Phi$ e were measured in the air with various $\mathrm{CO}_{2}$ concentrations to observed the relationship between these two parameters. The results are shown in Fig. 2. Фe of the C4 subtypes decreased with CER depression caused by a reduction in $\mathrm{CO}_{2}$ concentration, and the decreasing trend of $\Phi$ e was more conspicuous in corn. The specific feature shown in Fig. 2 was almost similar to the result in Fig. 1. This may suggest that the 


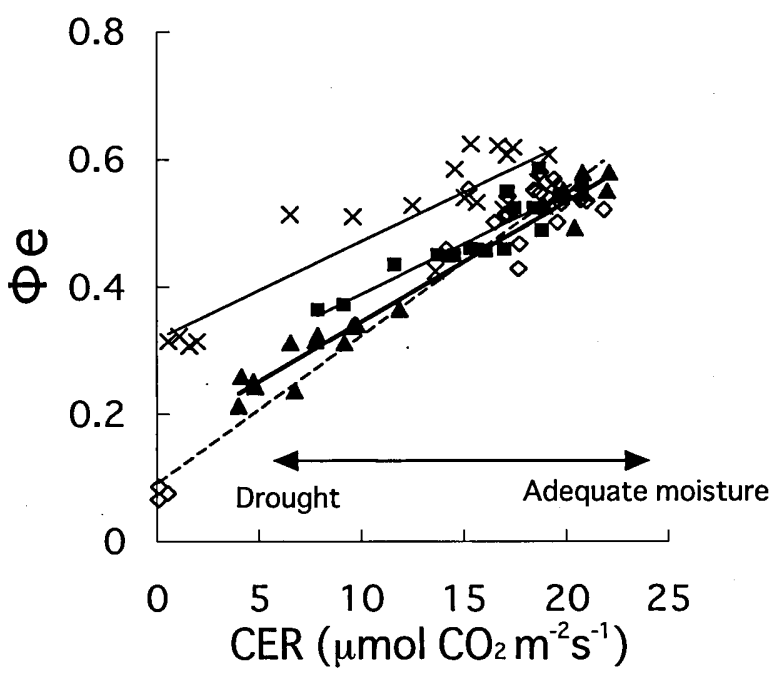

Fig. 1. The relationships between quantum yield ( $\left.\Phi_{c}\right)$ and $\mathrm{CO}_{2}$ exchange rate (CER) in corn ( $\diamond$, NADP-ME type), common millet $(\boldsymbol{\square}$, NAD-ME type), guineagrass $(\boldsymbol{\Delta}$, PEP-CK type) and mung bean ( $X$, C3 plant) measured under various soil water conditions.

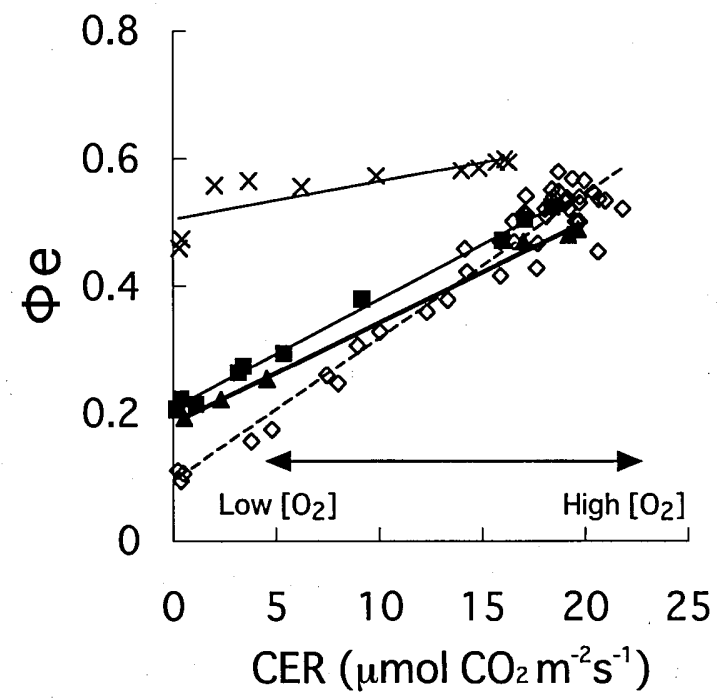

Fig. 2. The relationships between quantum yield $(\Phi \mathrm{e})$ and $\mathrm{CO}_{2}$ exchange rate (CER) in corn ( $\diamond$, NADP-ME type), common millet ( $\boldsymbol{\square}$, NAD-ME type), guineagrass $(\boldsymbol{A}$, PEP-CK type) and mung bean ( $\times$, C3 plant) measured in different $\mathrm{O}_{2}$ concentrations in the air. 


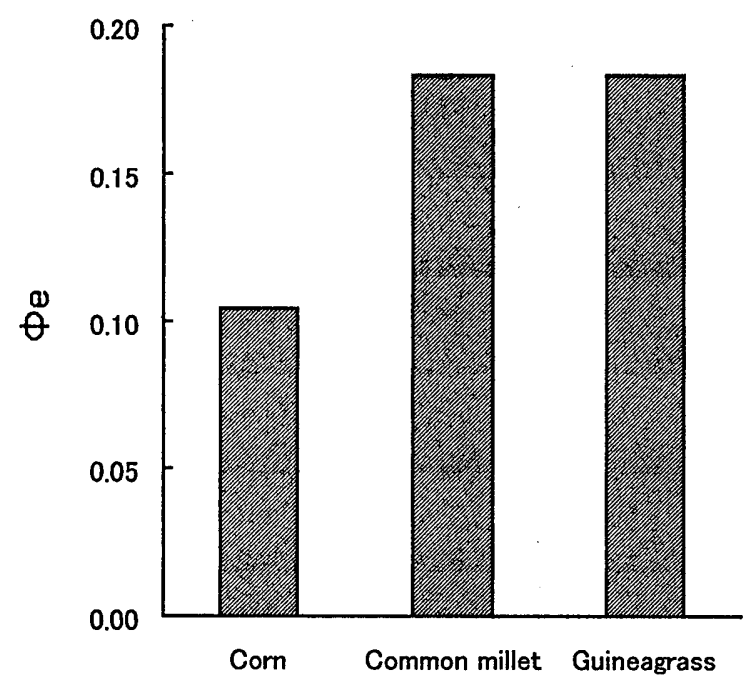

Fig. 3. The quantum yields ( $\left.\Phi_{e}\right)$ measured with film-sealed leaves in corn (NADP-ME type), common millet (NAD-ME type) and guineagrass (PEP-CK type).

inter-subtype differences in $\Phi$ e and photorespiration activity are more definitely shown when the carboxylation activity is more greatly restricted.

Then the leaf-sealing method was employed to restrict carboxylation in a leaf. In this method, both surfaces of a leaf are sealed with transparent films to stop the gas exchange. By monitoring the chlorophyll fluorescence, the electron transporting status inside the sealed leaf is diagnosed. As shown in Fig. 3, there was a significant difference in $\Phi$ e of sealed leaves between the C4 subtypes: the parameter value was high in common millet and guineagrass, and low in corn. This result may correspond to the inter-subtypical and inter-specific differences shown in Fig. 2 and 3. In the atmospheric air, C4 plants have almost no photorespiration, but under the condition where the intercellular $\mathrm{CO}_{2}$ concentration is reduced by restricting the gas exchange by sealing, the latent photorespiration metabolism is activated and the specific difference in photorespiratory activity may become apparent among C4 plants. The water-water cycle is a different energy-consuming metabolism other than photorespiration (Makino et al., 2002). But in our experiment the light intensity used was $504 \mu \mathrm{mol} \mathrm{m}^{-2} \mathrm{~s}^{-1}$, then it may be considered that in such a low light intensity the action of this cycle did not significantly affect the consumption of chemical energy.

The level of $\Phi$ e has been often used as one of the parameters indicating the activity of photorespiration. Of the three subtype species used here, corn (NADP-ME) was characterized by having a comparatively low $\Phi$ e when the CER was restricted. This may suggest that corn is a species having no or quite poor foundations for photorespiration, and as the result, this species was readily damaged under drought conditions and showed a less recovery in photosynthesis under the re-watering treatment. The leaf sealing 
method is expectantly available to diagnose the photorespiration potential and drought tolerance in C4 subtype species, but further studies using a more variety of materials are necessary to make clear the relationship between photorespiration and drought resistance in leaf photosynthesis.

\section{REFERENCES}

Bilger W. and O. Björkman 1990 Role of the xanthophylls cycle in photoprotection elucidated by measurements of light-induced absorbance changes, fluorescence and photosynthesis in lives of Hedera canariensis. Photosynthesis Research, 25: 1169-79

Genty B., J. M. Briantais and N. R. Baker 1989 The relationship between the quantum yield of photosynthetic electron transport and quenching of chlorophyll fluorescence. Biochimi. Biophys Acta, 990: 87-92

Haimeirong, F. Kubota and Y. Yoshimura 2002 Estimation of photosynthetic activity from the electron transport rate of photosystem 2 in a film-sealed leaf of sweet potato, Ipomoea batatas Lam. Photosynthetica, 40(3): 337-34

Krall J. P. and G. E. Edwards 1992 Relationship between photosystem II activity and $\mathrm{CO}_{2}$ fixation in leaves. Physiol. Plant., 86: 180-187

Ku M. S. B., M. Gutierrez, R. Kanai and G. E. Edwards 1974 Photosynthesis in mesophyll protoplasts and bundle sheath cells of various types of $\mathrm{C} 4$ plants. II. Chlorophyll and Hill reaction studies. $Z$. Pflanzenphysiol., 72: 320-337

Makino A., C. Miyake and A. Yokota 2002 Physiological functions of water-water cycle (Mehler reaction) and the cyclic electron flow around PSI in rice leaves. Plant Cell Physiol., 43(9): 1017-1026

Nagasuga K., F. Kubota and C. Nishiyama 2002 Specific difference in water transport regulation in two high-productive C4 crops, Napiergrass, Pennisetum purpureum Schumach and Maize, Zea mays L., Grown in different light intensities. J. Fac. Agr., Kyushu Univ., 46(2): 267-274

Sato A., Y. Yoshimura and F. Kubota 2001 Comparison of photosynthetic efficiency of C3 and C4 plants by leaf sealing method. Jpn. J. Crop. Sci., 70(2): 305-306

Ueno O. 2001 Ultrastructural localization of photosynthetic and photorespiratory enzymes in epidermal, mesophyll, bundle sheath and vascular bundle cells of the a C4 dicot Amaranthus viridis. J. Exp. Bot., 52: 1003-1013

$\mathrm{Xu} \mathrm{H}$. and R. Isii 1996 Wheat cultivar differences in photosynthetic response to low soil water potentials. 1. Maintenance of photosynthesis and leaf water potential. Jpn. J. Crop Sci., 65: 509-517

Yoshimura Y., A. Sato and F. Kubota F 2001 Comparison of photosynthetic efficiency in C3 and C4 subtypes by simultaneous monitorings of $\mathrm{CO}_{2}$ gas exchange rate and chlorophyll fluorescence quenching. Jpn. J. Crop. Sci., 70(2): 303-304

Yoshimura Y., F. Kubota and O. Ueno 2003 Quantitative characterization of photorespiratory organelles in C3 and C4 plants. Jpn. J. Crop Sci., 72(2): 358-359 